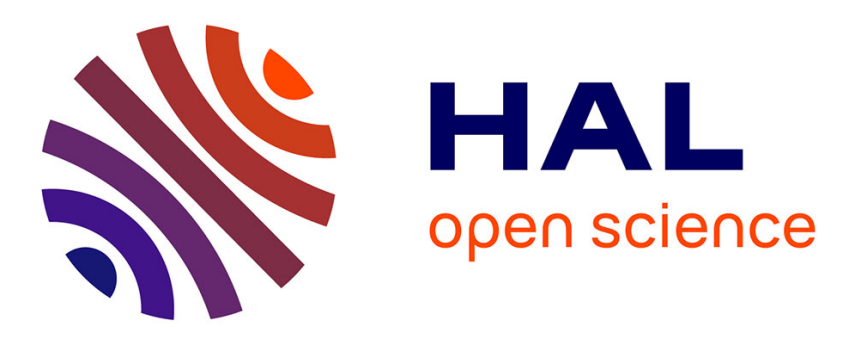

\title{
The interaction of fine particles with laser-generated nonlinear surface acoustic waves
}

\author{
V. Mikhalevich, Al. Kolomenskii, E. Benck, H. Schuessler
}

\section{To cite this version:}

V. Mikhalevich, Al. Kolomenskii, E. Benck, H. Schuessler. The interaction of fine particles with laser-generated nonlinear surface acoustic waves. Journal de Physique IV Proceedings, 1994, 04 (C7), pp.C7-709-C7-711. 10.1051/jp4:19947166 . jpa-00253226

\section{HAL Id: jpa-00253226 https://hal.science/jpa-00253226}

Submitted on 1 Jan 1994

HAL is a multi-disciplinary open access archive for the deposit and dissemination of scientific research documents, whether they are published or not. The documents may come from teaching and research institutions in France or abroad, or from public or private research centers.
L'archive ouverte pluridisciplinaire HAL, est destinée au dépôt et à la diffusion de documents scientifiques de niveau recherche, publiés ou non, émanant des établissements d'enseignement et de recherche français ou étrangers, des laboratoires publics ou privés. 


\title{
The interaction of fine particles with laser-generated nonlinear surface acoustic waves
}

\author{
V.G. Mikhalevich*, Al.A. Kolomenskii*, E.C. Benck and H.A. Schuessler \\ Department of Physics, Texas A\&M University, College Station, TX 77843-4242, U.S.A. \\ * General Physics Institute, Moscow 117942, Russia
}

\begin{abstract}
The cleaning of a silicon surface from dust particles using laser-induced suface acoustic pulses is investigated. It is shown that nonlinear acoustic waves displace particles not only perpendicular but also parallel to the surface and are therefore more effective in particle removal than are linear acoustic waves.
\end{abstract}

\section{INTRODUCTION}

In modern integrated circuit technology [1] the development of semiconductor processing free of fine particles becomes increasingly important. The traditional surface cleaning techniques are not effective at the submicron level and new methods for detaching submicron sized particles are needed. The recently proposed method of removing submicron size particles from surfaces with laser-generated surface acoustic waves (SAW) [2] provides an effective means for surface cleaning as well as for the investigation of the adhesive forces of fine particle to surfaces. The principal interaction that is represented in the adhesion of micron sized particles to solids is a molecular interaction based on the Van-der-Waals forces. With the decrease of the particle's dimension the role of the attractive forces between the particle and the substrate strongly increases and more and more intensive acoustic waves become necessary to remove the particle. For example the adhesion force of a micron size particle of $\mathrm{Al}_{2} \mathrm{O}_{3}$ with a mass of $2 \times 10^{-12} \mathrm{~g}$ located on a silicon surface in air is $\mathrm{F}_{\mathrm{ad}}=9 \times 10^{-3}$ dyn. In order to detach the particle the creation of a vertical acceleration equal to $4.5 \times 10^{6} \mathrm{~g}$ is needed. Here $g$ is the gravitational acceleration. For the same amplitude a nonlinear pulse rich in high frequency harmonics produces higher accelerations as compared with a linear one. For nonlinear SAW interacting with a particle on a surface in addition a newly observed effect arises, namely the displacement of particles along the surface.

\section{THEORY}

The analysis of the structure of a nonlinear Rayleigh wave [3] shows that a shock wave is formed along its horizontal component whereas in the vertical component the velocity of the medium displays a sharp spike. When the center of the shock movement passes the particle the surface experiences a large acceleration in the direction opposite to the direction of the SAW propagation and the inertial force shifts the particle along the surface in the direction of 


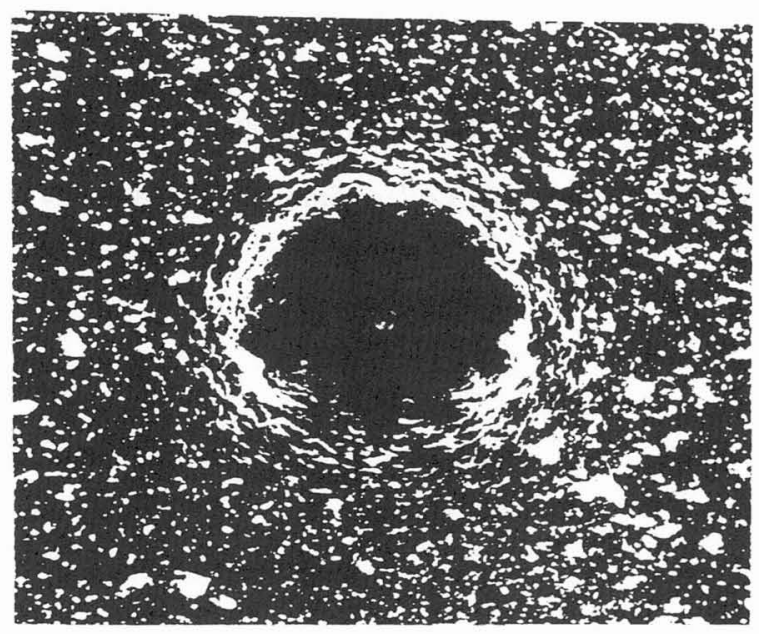

Fig. 1 Photograph taken with an optical microscope showing the removal of particles around the place of the repetitive pulsed laser action. The formation of a crest in the particle distribution is noticeable as result of a horizontal displacement of the particles.

the SAW propagation. In all the other moments of the passage of the acoustic wave namely when the surface restores its position a comparatively smaller positive acceleration occurs and the particle is kept on the surface and moves together with it. As a result a sequence of SAW pulses produces a net drag on a particle along the surface in the direction of the SAW propagation. Simultaneously the formation of a spike in the profile of the vertical velocity component at the center of the wave causes a strong increase of the vertical acceleration. The ultimate values of the inertial force are realized at this moment and will overcome the adhesion force when detaching the particle.

\section{EXPERIMENT}

In our experiments we studied the interaction of nonlinear SAW pulses with fine particles on the surface of a commercial silicon wafer. The wafer had a thickness of $380 \mu \mathrm{m}$ and was dusted uniformly with $1-2 \mu \mathrm{m}$ sized $\mathrm{A}_{2} \mathrm{O}_{3}$ particles. The $S A W$ pulses were excited by a Molectron UV-24 nitrogen laser with a wavelength of $\lambda=337 \mathrm{~nm}$, a pulse duration of $\tau=10$ $\mathrm{ns}$, an energy of $E=6 \mathrm{~mJ}$, and a repetition rate of up to $50 \mathrm{~Hz}$. The laser beam was focused on the sample surface producing a focal spot of dimension $150 \times 800 \mu \mathrm{m}$. The laser intensity was high enough to produce optical breakdown on the sample surface with (100) orientation which in turn creates an intense nonlinear SAW pulse. Due to the large size of the focal spot phonon focusing [4] is not visible.

\section{RESULTS}

Fig. 1 displays a photograph of the surface of the silicon wafer after exposure to 50 laser pulses. A pronounced pattern showing a horizontal displacement of particles is observable in the region close to the focal spot of the laser where the nonlinear SAW pulse is generated. It 
was also observed experimentally that the removal of the particles is facilitated when simultaneously with the acoustical pulse a weak flow of gas is directed on the surface.

This work is supported by a Teledyne Research Assistance Grant, DOE, and the Center for Energy and Mineral Resources of Texas A\&M University.

\section{References}

[1] M. B. Ranade, Aerosol Sci. Tech. 7, (1987) 161.

[2] Al. A. Kolomenskii and A. A. Masnev, Sov. Tech. Phys. Lett. 17 (1991) 483.

[3] E. A. Zabolotskaya, J. Acoust. Soc. Am. 91 (1992) 2569.

[4] Al. A. Kolmenskii, A. A. Maznev, V. G. Mikhalevich, and H. A. Schuessler. This conference. 